\title{
FENOMENOLOGIA E RELIGIÃO: APROXIMAÇÕES E REFLEXÕES SOBRE ESTE ESPAÇO ATRAVÉS DO ESPAÇO
}

\author{
Phenomenology and Religion: Approaches and reflections on this space through space
}

Alex Ander de Souza Orengo ${ }^{1}$

\section{RESUMO}

As grandes transformações da ciência não ocorrem na rotina mas exatamente na possibilidade de se pensar no limite desta rotina na qual os pesquisadores se encontram. Este artigo, através de uma visão panorâmica apoiada por uma breve revisão bibliográfica, reflete sobre a possibilidade do que seja pensar de forma a dirigir a mente na direção do inusitado e produzir aquelas grandes transformações que impulsionam o conhecimento.

Palavras-chave: Mudança; desenvolvimento da ciência; filosofia da ciência; fenomenologia.

\begin{abstract}
The great transformations of science do not occur in routine but precisely in the possibility of thinking about the limits of this routine in which researchers find themselves. This article, through a panoramic view supported by a brief bibliographical review, reflects on the possibility of thinking in order to direct the mind towards the unusual and produce those great transformations that drive knowledge.
\end{abstract}

Keywords: Change; science development; philosophy of science; phenomenology.

\section{Um início lúdico - O Sr. X}

Certa vez, quando ainda estava na faculdade, assisti uma palestra sobre as teorias de Einstein, onde um exemplo foi utilizado e com o qual desejo iniciar esta reflexão. Em determinado momento o palestrante nos convidou a imaginar um mundo bidimensional; em seguida, sugeriu que concebêssemos um Sr. X, habitante deste mundo fictício e, portanto, também bidimensional. O Sr. $\mathrm{X}$ havia nascido naquele mundo e ali vivera a sua vida inteira. O orador sugere então que o Sr. X é transportado para uma realidade tridimensional, passando a sustentar a tese de que nesta situação o Sr. X seria incapaz de perceber a tridimensionalidade daquele novo mundo. Exatamente por sua condição e experiências bidimensionais.

\footnotetext{
${ }^{1}$ Doutorando em Geografia pela Universidade Federal do Paraná - UFPR/PR. Mestre em Psicologia Clínica pela Universidade Federal do Paraná - UFPR/PR (2018). Pós-graduado em Marketing, Comunicação e Negócios pela Universidade da Região de Joinville - UNIVILLE/SC (2000. Graduado em Engenharia Química pela Universidade Federal do Rio Grande - FURG (1992).
} 


\section{Realidades não percebidas - Naturalização}

Tomo este exemplo como pano de fundo e aquecimento introdutório a esta ponderação, procurando reter dele somente o fato de o Sr. X não perceber outra realidade diferente da sua. Poderíamos nos perguntar: o que conseguiríamos perceber, se fôssemos levados para um mundo quadridimensional? Será que similarmente ao Sr. X não conseguiríamos perceber a dimensão adicional? Como saber... Bem, talvez como exercício filosófico estas ponderações tenham espaço, embora possamos questionar sua importância no âmbito prático. De qualquer forma, algo que é inquestionável é a existência de realidades distintas daquelas que conhecemos, que defendemos e que vivenciamos neste nosso mundo tridimensional. Não sendo necessário pensarmos ou concebermos mundos pluridimensionais para ter ciência deste fato.

A diversidade de realidades não percebidas está aí, está dada. Fruto de nossas diferentes formações, fruto de nossas diferentes criações, fruto de nossas diferentes experiências. Aqui, com a devida licença poética, poderíamos trazer à baila inclusive a visão de Fernando Pessoa (2006) sobre isto, quando faz menção ao que vemos senão aquilo que somos. O que nos leva à extrapolação de possibilidades: como cada ser humano está sempre sendo, teremos, portanto, uma realidade vista para cada um de nós, seres humanos; caracterizando assim, de forma similar ao exemplo do Sr. X, realidades desconhecidas às quais podemos - e constantemente somos - expostos, o que não necessariamente nos leva a percebê-las.

Este nosso estar no mundo, a forma como o percebemos e interpretamos, nos é particular. Como citado, percepções e interpretações são frutos de nossa história: da família onde nascemos, da educação que nossos pais e parentes tiveram, da educação que recebemos desta família... Fruto das vizinhanças onde moramos, dos amigos que tivemos, das escolas que estudamos e dos professores que nos orientaram... Consequências dos livros que lemos e das músicas que escutamos... Bem como, frutos também daquelas vizinhanças onde não moramos, das famílias que não tivemos, dos professores que não nos orientaram e de todas as experiências que não vivemos. Somos, portanto, consequência de presenças - experiências vividas - e ausências - experiências não vividas (SOKOLOWSKI, 2012). Constatação que nos leva naturalmente a outra: na medida em que vivemos uma experiência particular, uma gama enorme de outras experiências não estamos vivenciando; pois, na medida em que vivemos uma experiência, vivemos àquela e não outras, mas 
aquela. Entretanto, todas as escolhas que não fizemos, todas as experiências que não vivemos, se multiplicam, existindo um em volume imensamente superior às vividas; nos possibilitando constatar que somos mais fruto de ausências do que de presenças. Ausências essas que deixaram suas consequências em nossa constituição, nos marcando de algum modo. Ausências que assim, se fizeram presentes. Nos permitindo concluir, que ausências também são presenças.

Este mosaico de presenças e ausências, experiências vividas e não vividas, nos constituiu da forma que somos, possibilitando que tenhamos a partir disso, uma maneira de olhar, de perceber o mundo e interpretá-lo. Pois se tivéssemos nascido em outra família, se tivéssemos tido outros professores, se tivéssemos morado em outras vizinhanças, seríamos diferentes e com outro ponto de vista sobre a realidade.

\section{Um exemplo - O espaço}

Neste ponto, poderíamos nos questionar sobre o porquê de indivíduos que viveram as mesmas experiências possuírem olhares distintos sobre o mundo. Uma hipótese é que tais indivíduos não viveram a experiência da mesma maneira. De qualquer forma, seja pelo fato de vivermos experiências diferentes ou por vivermos de formas diferente as mesmas experiências, nossas percepções e interpretações do mundo podem ser - são - diferentes. Então, não precisamos ser levados a outro tipo de mundo, como o Sr. X, para estarmos expostos a situações que não percebemos, uma vez que estamos rodeados por elas.

Um fenômeno que atinge essas percepções e interpretações é a naturalização. Quando passamos a achar, ou entender como normal, como natural, determinadas coisas; sem as questionar nem analisar. Tomemos aqui um exemplo cotidiano: o trajeto de casa ao trabalho. De tão expostos que somos à monotonia e à rotina do caminho, passamos a não ter mais estranhamento sobre a paisagem, chegando inclusive a nos tornar cegos para determinados trechos, onde a mente divaga nos levando a nem perceber que passamos por determinado ponto, como se agíssemos no automático. Assim, formas de fazer determinadas coisas, convenções sociais, ações cotidianas e conceitos, entre outras tantas situações que poderíamos listar, recebem um invólucro de condição absoluta, de verdade; passam a ser para nós, verdade. Passam a ser entendidas como a forma correta de fazer, como a forma correta de interpretar, como a forma correta de viver, pois foi assim que aprendemos, pois foi assim que sempre foi feito, pois foi assim que nos ensinaram. 
Aqui podemos novamente retornar ao paralelo com o Sr. X. Ele sempre viveu em um mundo bidimensional, um ambiente para ele, normal, natural. Nós, por outro lado, sempre vivemos em um mundo tridimensional, que para nós é normal e natural. Neste ambiente nascemos e fomos educados e tivemos inicialmente a experiência, provavelmente não consciente, de espaço, vivenciando-o, para mais tarde na caminhada de nossa formação educacional e escolar, sermos informados cientificamente, matematicamente, geometricamente, sobre sua tridimensionalidade. O que não fez o espaço, ou a experiência de espaço, deixar de ser natural para nós. E assim, natural como o espaço, é natural que tudo se desenvolva e aconteça no espaço. Não é estranho que as coisas aconteçam no espaço e a vida se dê no espaço. E não raro, tão pouco questionamos nossa relação com o espaço e a relação de nossas representações e conceitos com o espaço. Pois ele faz parte de nossas experiências desde sempre e assim como as nuances do trajeto de casa ao trabalho, tende a passar despercebido pela nossa atenção.

Entretanto, se desnaturalizarmos esta relação que estabelecemos com o espaço, podemos nos direcionar para percepções e interpretações que talvez não nos sejam próximas, nos possibilitando a experiência de outros olhares para este ambiente que inicialmente nos parece tão rotineiro e monótono. Um meio de procedermos esta desnaturalização é através do pensar as espacialidades estabelecidas.

\section{Espacialidades}

O cenário no qual buscamos delinear as premissas conceituais deste trabalho é marcado pela obra de Ernst Cassirer (2001, 2004, 2011), especificamente a sua “Filosofia das Formas Simbólicas”, onde aborda o relacionamento do homem com o mundo que o cerca e as nuances deste relacionamento, intermediado pelas formas simbólicas. Estas seriam como canais através dos quais captamos o mundo, lhe conferimos sentido, estabelecemos nossas representações e conceitos, e a partir daí dispondo de um ferramental que nos possibilita viver, interagindo e dispondo deste determinado mundo. Cassirer (2001) cita como Formas Simbólicas: o mito, a religião, a linguagem, a arte e a ciência.

Mas é interessante ressaltar que este mundo com o qual interagimos, não é o mundo ou o espaço para sermos menos metafísicos e mais específicos - geométrico, tridimensional ou Euclidiano, mas o engloba e transcende; um espaço marcado e construído pelas ações e experiências do indivíduo, 
estabelecendo o mundo onde de fato vivemos: um espaço simbólico (FERNANDES, GIL FILHO, 2011; GIL FILHO, 2012). Este mundo é o mundo da cultura (SILVA, 2018), formado pelo homem através de sua atividade simbólica, ou seja, a partir da vivência/experiência do espaço físico, através da mediação das formas simbólicas. A este conjunto de significado, à estruturação do espaço como consequência da significação, com a posterior ação e interação com este espaço a partir da significação e estruturação, consideramos como espacialidade; ou seja, uma maneira de interpretar e agir no espaço físico, tendo como referência imediata um espaço simbólico, espaço este plasmado pela ação simbólica (GIL FILHO, 2012), via mediação das formas simbólicas.

\section{Desnaturalização}

Se por naturalização tomamos como a ação de encarar como natural, como verdade tácita, uma determinada situação baseada em representações, a desnaturalização é a ação contrária e necessária. Assim, nossa proposta é proceder à desnaturalização através do questionamento de espacialidades, uma vez que estas traduzem representações. E este questionamento é um processo de análise das espacialidades, uma depuração, um esmiuçamento de atitudes, hábitos e produções que temos como sociedade; tirando aquelas que nos interessam desta vala comum da naturalização para olhálas com atenção.

Resgatemos rapidamente nosso trajeto até aqui. Refletimos sobre como temos percepções sobre o mundo e como naturalizamos aspectos deste relacionamento; apresentando uma possibilidade de conhecimento de outras percepções, para nós desconhecidas, através da análise de algumas espacialidades, já que estas traduzem percepções e ditam comportamentos no espaço e a partir dele; tendo como pano de fundo na condução desta perquirição, a Filosofia das Formas Simbólicas de Cassirer.

Estabelecidas estas premissas introdutórias, nos direcionemos ao nosso foco. Como vimos, por estarmos imersos no espaço desde sempre, muito de nossa relação com o espaço é naturalizada. Muito facilmente ao falarmos de espaço, nos remetemos ao espaço sideral ou à distância entre corpos (tanto física quanto metafísica), quando nos referimos a ter espaço para expressar-nos ou espaço para exercer a liberdade, entre tantos outros exemplos que possam ser dados nessa direção. Mas o espaço enquanto construção simbólica, como vimos, tem mais a nos apresentar. 
Uma vez que nos afastamos da vida na natureza, criamos um espaço que nos transmita segurança e possua tudo aquilo que cremos ser necessário à sobrevivência: criamos as cidades como expressão deste sentimento e necessidades (GIL FILHO, 2018), como espacialidade, enfim. Nas cidades dispomos de comida, de abrigo e de água; temos um espaço onde cada uma destas utilidades será produzida e disponibilizada; as cidades apresentam ainda um plano diretor, que traduz inicialmente uma ideia de organização e posteriormente a organização das atividades no espaço e do uso deste espaço. Existem áreas destinadas a moradias e áreas destinadas a circulação; áreas destinadas ao trabalho e áreas destinadas ao lazer; áreas destinadas ao convívio social e áreas privativas; áreas destinadas a administração, áreas destinadas para a espiritualidade e áreas destinadas ao ensino. Por outro lado, ainda, as divisões de terreno espacializam a concepção de posse e apropriação do espaço. Conceitualizamos áreas como rurais e outras como urbanas. E assim tantas outras caracterizações.

\section{Espacialidades Espirituais}

Particularizando ainda mais a nossa análise, centremos foco sobre as espacialidades espirituais ou dizendo de outra forma, sobre os espaços ligados a práticas religiosas. Sendo espacialidades, estas práticas, apresentam os mesmos processos de formação e projeção, enquanto ação no espaço, que qualquer outra espacialização, possuindo somente um conteúdo e uma expressão distintas. Mas exatamente por trazer em seu bojo tais conteúdos e tais expressões que as tomaremos para reflexão. Assim como as demais espacialidades, encontramos aqui uma projeção de representações no espaço, espaço de ação, marcando um processo de significação simbólica e de interpretação, de percepção inclusive, do mundo, via formas simbólicas (CASSIRER, 2001) com o posterior e consequente estabelecimento de formas de ação e relacionamento neste e com este espaço. De qualquer forma, o conteúdo da qual tratam chama a atenção, pois um traço comum a todos os povos é a relação com o sagrado e suas expressões (ELIADE, s/d, 1991), sendo estas, espacialidades.

Diante destes contornos, apresentamos hipóteses. Podemos preliminarmente nos perguntar sobre como a humanidade ensina, ou aprende sobre o sagrado? Uma vez que nascemos em uma sociedade constituída com seus hábitos, costumes e valores, aprenderemos e apreenderemos já, por simplesmente estarmos nesta sociedade, reproduzindo os costumes e eventualmente, a posteriori, através de uma orientação formal? Dito de outra forma, nascemos imersos em representações e 
espacialidades que irão invariavelmente nos inculturar, deixando seus traços de forma ora mais profunda, ora de forma mais tênue. Importante ressaltar aqui, que não há, neste pensar, um reducionismo estruturalista nem determinístico, ou uma obliteração de liberdade. Procuramos somente ilustrar o fato de que uma vez convivendo com determinada sociedade, este modus operandi social, de alguma forma, fará parte das referências e histórias de vida do indivíduo; com alguns traços sendo incorporados eventualmente com mais força, e outros nem tanto, mas de qualquer forma, fazendo parte do cabedal de conhecimentos do sujeito. A outra questão que podemos apresentar é quanto deste aprender/ensinar sobre o sagrado é espacial? Podemos até ampliar esta ilação pensando na educação de uma forma mais ampla: é possível falarmos em um ensino espacial? É possível falarmos em uma didática espacial? E ambos, não seriam essencialmente espaciais, uma vez que é no espaço de ação que as expressões e percepções do sensível se manifestam e existem (GIL FILHO, 2012)? De qualquer forma, a questão sobre o aprendizado do sagrado está, obviamente, inserida nestas questões maiores, nos permitindo fazer as mesmas indagações em relação a ele. Resgatando o raciocínio apresentado no início do trabalho, de forma a ir amarrando as pontas, cremos que perquirições assim, podem nos levar na direção da desnaturalização deste traço cultural que nos acompanha desde sempre, exatamente por nos possibilitar um olhar de estranhamento sobre ele.

Buscando respostas aos questionamentos, podemos iniciar com as expressões, ou espacialidades, mais marcantes no âmbito do sagrado. Podemos nos ater aos rituais fúnebres, que datam da préhistória e traduzem como os indivíduos procuravam tratar suas questões psíquicas e sentimentais relacionadas ao falecimento de entes significativos ou representativos, além da organização social que seria necessária a partir dali (SOUZA; SOUZA, 2019). Outro bom exemplo vindo das brumas do tempo, é a sociedade céltica e os druidas, que marcavam os eventos estelares e o comportamento da natureza, como solstícios e equinócios, a movimentação de corpos celestes por exemplo, bem como as estações do ano, através de calendários e complexos arquitetônicos (KNIGHT; LOMAS, 2002, 2006, 2007; OLIVIERI, 2008). Aqui, novamente, demonstrando a estruturação do espaço com base em um conjunto de crenças e pressupostos místico-espirituais, além de práticos, para a marcação da época de plantio e colheita. Comportamentos e expressões similares são encontrados nas Américas, como em Chankillo (SUAREZ; SILVA, 2020) e nas estruturas no entorno e no complexo de Machu Picchu, no Peru; nas construções em Chichen Itza (VICTORIA; 
ZIÓŁKOWSK; KOŚCIUK, 2017) e Teotihuacán (SMITH, 2020), no México; bem como nas estruturas Anasazi nos Estados Unidos (SAGAN, 1980). Todas estas construções destinadas à prática de rituais ligados ao relacionamento com o que cada um destes povos entendia como sagrado, marcando fisicamente pontos importantes de seus sistemas religiosos e das suas crenças. Outros exemplos que podemos tomar de espacialidades vindas do relacionamento com o sagrado, são relatadas em etnografias clássicas, como o trabalho de Malinowski (1978) ao tratar do kula entre os polinésios, que estabelece uma forma de trocas comerciais e de sentido de navegação entre as ilhas do extremo oriental da Nova Guiné; bem como os estudos de Evans-Pritchard (2005) sobre as práticas Azande de bruxaria e magia, e da religião Nuer (ARANHA; FREIRE; MENEZES, 2015) que apresentam justificativas e explicações para eventos físicos e moldam as relações sociais como um todo.

Casos mais próximos ao cotidiano podem ser abordados. Os rituais fúnebres da nossa sociedade levaram ao estabelecimento de capelas mortuárias, crematórios e cemitérios nas cidades, reservando espaços exclusivamente destinados à condução de espacialidades frutos do relacionamento que estabelecemos com a morte e com nossas crenças espirituais (ARAÚJO, 2014). Também encontramos espaços exclusivamente destinados às práticas religiosas e à vivência das rotinas das várias religiões, expressões de espiritualidades ou filosofias de vida, sejam espaços marcados por construções e prédios ou por áreas abertas. Afinando o olhar, poderemos ainda perceber que em cada um destes espaços particulares ainda existem divisões, destinando ou consagrando espaços para que ali se realizem rituais ou parte destes, conforme as peculiaridades de cada instituição: oferendas, consagrações, iniciações, ensino, batismos, bençãos, preleções, meditações, incorporações, reuniões e debates, entre outros. E para cada um destes locais havendo uma postura e um comportamento adequado e esperado; posturas e comportamentos que vão sendo aprendidos, como citamos, na medida em que os indivíduos participam dos rituais orientados por outros já mais familiarizados com eles ou através de instruções formais e institucionalizadas.

Então, o participar da vida espiritual, do relacionamento com o sagrado, conforme a comunidade a qual pertença, se dá em espaços específicos onde ficam as instalações daquela instituição; nestes espaços, os executores e postulantes dos rituais, assim como os participantes, ocuparão espaços distintos; conforme as cerimônias previstas para o serviço os espaços mudam, bem como aqueles que estão autorizados a ocupá-los; para cada espaço temos práticas e atitudes próprias a serem 
executadas; em alguns casos, nota-se inclusive uma mudança de vocabulário entre aquele que é utilizado no espaço profano frente aquele do espaço sagrado; o mesmo sendo observado com roupas e adornos.

Defendemos que estas nuances todas aparecem pela relação última que se estabelece com o espaço, enquanto espaço de ação; este espaço que é utilizado para expressar representações constituídas através de um processo fenomênico simbólico, com a atuação das formas simbólicas como canais de leitura e apreensão da realidade. Portanto, geradas a partir do espaço e materializadas e vividas enquanto espacialidades; possibilitando considerar o espaço, como um dos elementos fundamentais do aprendizado religioso, de forma restrita, e da formação do indivíduo de forma ampla; onde a cultura é criada, manifesta e repassada, em suas expressões, valores, costumes e estruturas.

Procuramos aqui - tomando como foco a Fenomenologia, seguindo ainda o caminho de Cassirer tomando o espaço do sagrado e suas espacialidades para pensar de forma nova este ambiente. Mas muitas outras formas nos instigam a pensar assim e visualizar outras possibilidades. É o que encontramos aqui, através das contribuições de outros autores, neste Dossiê sobre Fenomenologia e Religião.

\section{Outras desnaturalizações possíveis - Pensar nos limites}

Seja você um leitor habitual deste veículo, seja você um pesquisador, seja você um curioso, ou tenha você encontrado este sítio em meio a suas buscas e pesquisas na rede, seja bem-vindo. E desejamos recebê-lo sob os auspícios de novas possibilidades; sob a perspectiva do inusitado; junto ao limiar da possibilidade de visão, das desnaturalizações, do entendimento e pensamento destas áreas - Fenomenologia e Religião -, sobre as quais se debruça este dossiê.

Obviamente, supondo ser possível nosso intento de ineditismo e surpresa, em um mundo hoje, por si só, tão surpreendente; mas também tão naturalizado. E se surpreendente desejamos que seja este encontro, de forma a abordarmos e compartilharmos temas tão inusuais em seus vieses, convidamos a comentários, vozes incomuns em publicações científicas, mas que nos darão luz e inspiração - já que tratamos também da área da religião - para reflexionarmos o que virá. O nome de Joel Barker não é escutado no meio acadêmico e hoje pouco escutado no mercado. Barker, consultor americano, teve uma grande projeção ao final dos anos oitenta ao apoiar empresas a se desenvolverem e se prepararem para o futuro, um lugar que na época era muito distante... embora 
já tenha chegado e nos chegue hoje, com uma frequência e com uma velocidade que nem Barker, nem outro expoente de projeção da época, este escritor e futurista, Alvin Toffler, poderiam imaginar. Barker (1994) após estudar a obra “A Estrutura das Revoluções Científicas” de Thomas Kuhn, passou a trabalhar com o conceito de paradigma no mundo empresarial e ao longo das suas exposições, trabalhava em dado momento com o que ele denominava de Lei da Mudança de Paradigma, traduzido em uma pergunta, que segundo ele pode nos levar aos limites do(s) paradigma(s) vigente(s): o que, que nunca foi feito, mas que se fosse feito, mudaria tudo? (BARKER, 1994). Sobre o uso desta pergunta, o consultor adverte: exercitá-la sem filtros impostos à mente, de forma a não cegar e/ou tolher o cérebro. A segunda voz que trazemos para abrir este trabalho já é bem mais conhecido de todos nós e não nos surpreenderia o fato de que neste momento você esteja acessando este conteúdo através de algum aparelho que este personagem desenvolveu: referimo-nos a Steve Jobs. Em uma vinheta sobre documentários em um determinado canal de nãoficção que leva o nome de um famoso museu americano, é veiculada uma cena, onde o então jovem Jobs, fala sobre inovação; algo como: se você deseja ver o futuro, não adianta olhar o cenário; você tem que olhar para as bordas.

O que estas duas vozes inusitadas apontam é, de modo muito interessante, a mesma coisa. Talvez hoje até já naturalizada, mas sempre importante de ser referendada: as grandes viradas de pensamento, as abordagens que instigam as mentes a pensar e que vêm desequilibrar e dar cor ao grande oceano da rotina da ciência, um oceano que se identifica no cotidiano muito mais com o Pacífico do que com o Atlântico dada a sua aparente calmaria, se encontram nos limites das possibilidades com as quais trabalhamos. Talvez possamos criticar a produção científica; por vez ou outra tratar dos mesmos temas de pequenas formas distintas, ou como se estivéssemos em um perpétuo auto doutrinamento; mas a questão não parece ser esta, pois a ciência avança de forma lenta na maioria das vezes, em que pese o contraponto contrário feito pela área de tecnologia, e deixando que diminutas gotas sejam adicionadas ao seu oceano a cada pesquisa acabada. Gotas que em si não farão as cidades costeiras serem inundadas, mas que se somadas, somadas, somadas ... ao infinito, o farão. Então não nos interessa aqui este andar quase que paquidérmico da ciência, mas sim as grandes vagas, os tsunamis que, vez por outra na história, ela proporciona. Bem, poderíamos ter a pretensão de afirmar que este Dossiê é um destes tsunamis. Seria uma grande pretensão. Não que não possa ser, mas não nos cabe aqui essa defesa. O que cremos ser interessante 
aventar é a possibilidade de não esperar que os tsunamis apareçam naturalmente, ou por uma conjunção aleatória de fatores, ou por puro capricho do destino; ou, nos aproximando da temática, que os deuses da ciência abençoem uma ou outra mente naquela dita manhã de quinta-feira, comum, esquecida no calendário e ali, quase que numa epifania, nasça outra grande revolução científica, ou ao menos - sejamos mais modestos - algo que seja de fato muito, mas muito diferente. Seguimos, portanto, na direção da nossa real possibilidade de criar as condições para os tsunamis, para as grandes revoluções. Pensar no não normal, olhar de formas nunca olhadas, perceber de formas nunca percebidas, trilhar linhas de raciocínio que talvez nos afastassem de nossos orientadores e pares; alçar o olhar naquela direção que nossas crenças e paradigmas até agora não permitiram. E fazer isso não por rebeldia, mas porque é ali que estará o novo. Daí, coerentemente ao raciocínio, termos começado esta apresentação de forma tão heterodoxa. Nossas vozes convidadas, não foram de fato nomes de ciência, mas indiscutivelmente criaram tsunamis; Barker na administração e Jobs na tecnologia.

\section{Considerações finais}

Na produção científica, vez ou outra. encontramos o inusitado, o novo. Edmund Husserl, ao colocar-se como crítico do caminho que a ciência tomava em sua época, não deve ter se feito a pergunta proposta por Barker e talvez não tenha seguido o conselho de Jobs, mas propôs soluções que se re-contextualizadas aos olhos destas duas possibilidades, caberiam perfeitamente como respostas.

Ao estabelecer a Fenomenologia como o fez, Husserl concede novamente a liberdade ao pensamento científico além de resgatar o sujeito e dar-lhe um lugar adequado no cenário do desenvolvimento epistemológico. Uma onda que de fato, inundou costas e ainda transforma litorais. É uma nova fundação da filosofia. E esta nova forma de olhar o mundo, ganhou um novo mundo, na medida em que cada vez mais pensadores e pesquisadores, na busca e na necessidade de novas bases epistemológicas, vieram se apoiar na Fenomenologia. Usos que proporcionaram novas aberturas, novas descobertas e até abertura de novos campos inteiros de perquirições.

Hoje encontramos a Fenomenologia na Medicina, no Direito, na Administração, na Educação Física, na Geografia, na História, na Pedagogia e na Educação, entre outras áreas, dando a elas a perspectiva do novo. No campo da Religião, embora com desenvolvimentos mais diluídos, pela 
proficiência de nomes envolvidos, o surpreendente também se apresentou. Até mesmo o passo dado na direção de estudar o sagrado temos que considerar que foi um grande passo; exatamente por esta sua natureza de ser “o” sagrado. E a Religião ganhou olhares vindos das mais variadas áreas: antropologia, sociologia, psicologia, geografia, história, além é claro da própria filosofia. Abarcando em seu bojo, não somente aquilo que explicitamente é sagrado, e que comumente entendemos ou aceitamos como sagrado, mas muito do que modernamente tem recebido a significação de sagrado e consequentemente, passando a ter estabelecido um relacionamento aos moldes do sagrado, tais como: política, futebol, games, figuras públicas, colecionáveis, linhas de pensamento epistemológicos e acadêmicos, para citar alguns. Demonstrando assim, como o tema Religião, de forma similar àquilo que ocorreu e ocorre com a Fenomenologia, também tem se debruçado no limiar da delimitação de seu campo, percebendo a surpresa e o inusitado se aproximando.

Ponderamos a possibilidade de que Fenomenologia e Religião possam se unir para criar um (novo) espaço ao novo, lançando o olhar aos limites, proporcionando a perspectiva do inusitado e a possibilidade de entendimentos outros. Estas áreas, não estão aqui como uma Fenomenologia da Religião, ou como Fenomenologia na Religião, ou ainda como a estranhíssima, se existisse, “Religião Fenomenológica” - e esta seria sim uma área de extrema surpresa, fazendo o velho Husserl levar as mãos à cabeça e dizer: “Pai, perdoai porque eles não sabem o que fazem!”. Fenomenologia e Religião; como dois campos sob os quais há possibilidade de pensar em igual peso e medida; voltando olhar em igual medida tanto para um como para o outro. Campos, configurando espaços, ora por estarem um sobre o outro, ora por estarem um ao lado do outro. De qualquer forma, sempre como se tivessem as incômodas sentenças como guia: não olhem o cenário, mas para as bordas; o que que nunca foi feito, mas que se fosse, mudaria tudo? E aí, talvez encontremos a viabilidade real de produzirmos o inusitado!

\section{REFERENCIAS}

ARANHA, A.; FREIRE, G.; MENEZES, H. Nuer religion. In: Enciclopédia de Antropologia. São Paulo: Universidade de São Paulo, Departamento de Antropologia. Disponível em: <http://ea.fflch.usp.br/obra/nuer-religion>. Acesso em: 11 fev. 2021. 
ARAÚJO, T. N. Hermenêutica e Cemitérios: um olhar sobre o cemitério da Santa Casa em Porto Alegre. Ciências Sociais e Religião, Porto Alegre, ano 16, n.20, p.82-95, jan-jun de 2014.

BARKER, J. A questão dos Paradigmas. Siamar. 1994.

CASSIRER, E. A Filosofia das Formas Simbólicas - I - A Linguagem. Tradução de Marion Fleischer. São Paulo: Martins Fontes. 2001.

. E. A Filosofia das Formas Simbólicas - II - O Pensamento Mítico. São Paulo: Martins Fontes. 2004.

E. A Filosofia das Formas Simbólicas - III - Fenomenologia do Conhecimento. São Paulo: Martins Fontes. 2011.

, E. Ensaio sobre o homem: Introdução a uma filosofia da cultura humana. São Paulo: Editora WMF Martins Fontes. 2012.

ELIADE, M. Imagens e Símbolos - Ensaio sobre o simbolismo mágico-religioso. São Paulo: Martins Fontes. 1991.

, M. O sagrado e o Profano - A essência das Religiões. Coleção Vida e Cultura. Lisboa: Edição Livros do Brasil. S/D.

EVANS-PRITCHARD, E. E. Bruxaria, Oráculos e Magia entre os Azande. $2^{\text {a }}$ Edição. Rio de Janeiro: Zahar. 2005.

FERNANDES, D; SYLVIO, G.F. Geografia em Cassirer: Perspectivas para a geografia da religião. GeoTextos, vol. 7, n. 2. 211-228. dez. 2011.

GIL FILHO, S. F. Geografia das Formas Simbólicas em Ernst Cassirer. In.: BARTHE-DELOIZY, Francine; SERPA, Angelo (orgs.). Visões do Brasil: estudos culturais em geografia. Salvador: EDUFBA, 2012. P. 47-66.

GIL FILHO, S. F. S. F. Seminário Temático II: Pregnância Simbólica. Curitiba, 2018. Aulas proferidas na Universidade Federal do Paraná.

KNIGHT, C.; LOMAS, R. A Chave de Hiram. São Paulo: Madras, 2002.

KNIGTH, C.; LOMAS, R. A Máquina de Uriel: As antigas origens da ciência. São Paulo: Madras, 2006.

KNIGTH, C.; LOMAS, R. O Livro de Hiram. 2ª Edição. São Paulo: Madras, 2007. 
MALINOWSKI, B. Argonautas do Pacífico Ocidental: um relato do empreendimento e da aventura dos nativos nos arquipélagos da Nova Guiné melanésia. $2^{\mathrm{a}}$ Ed. São Paulo: Abril Cultural. 1978.

OLIVIERI, F.L. O papel dos druidas na sociedade céltica na Gália nos séculos II e I A.C. 324 f. Tese (Doutorado em História) - História Social, Departamento de História. Universidade Federal Fluminense. Rio de Janeiro. 2008.

PESSOA, F. Autobiografia sem factos. Lisboa: Assírio \& Alvim, p. 360. 2006.

SAGAN, C. Cosmos. São Paulo: Livraria Francisco Alves. 1980.

SILVA, M.A.S. O espaço em Ernst Cassirer (1874-1945): contribuições para a epistemologia da geografia. XIX Encontro Nacional de Geógrafos.35412 Paraíba: Jul 2018.

SMITH, M.E. Mesoamerica's First World City Teotihuacan: in Comparative Perspective. In.: Teotihuacan: The World Beyond the City, edited by David M. Carballo, Kenneth G. Hirth and Barbara Arroyo. Dumbarton Oaks, Washington, DC: 2020. p. 33-56.

SOKOLOWSKI, R. Introdução à Fenomenologia. $3^{\text {a }}$ Ed. São Paulo: Edições Loyola. 2012.

SOUZA, C.P de; SOUZA, A.M. de. Rituais Fúnebres no Processo do Luto: Significados e Funções. Psicologia: Teoria e Pesquisa. V 35. e35412. 2019.

SUAREZ, R.S.; SILVA, L.L.I. Espacios de interpretación arqueoastronómicos y turismo científico. Centro de Interpretación arqueoastronómico en Chankillo. Monografia (Bacharelado em Arquitetura) - Facultad de Ingeniería y Arquitectur / Escuela Profesional de Arquitectura. Universidad Peruana Unión. Lima. 2020.

VICTORIA, F.A.; ZIÓŁKOWSK, M; KOŚCIUK, J. On Inca astronomical instruments: the observatory at Inkaraqay - El Mirador (National Archaeological Park of Machu Picchu, Peru). Estudios Latinoamericanos. 36/37. p. 9-25. 2016/2017. 